\title{
Comparison of Miniplate and K-wire in the Treatment of Metacarpal and Phalangeal Fractures
}

\author{
Zulfiqar Ahmed ${ }^{1}$, Muhammad Imran Haider ${ }^{1}$, M Iqbal Buzdar ${ }^{1}$, Babar Bakht Chugtai ${ }^{1}$, Majid Rashid ${ }^{2}$, \\ Nazar Hussain ${ }^{1}$, Farman Ali ${ }^{3}$ \\ 1. Orthopaedics, Bahawal Victoria Hospital, Bahawalpur, PAK 2. Orthopaedics, Sahiwal Medical College, Sahiwal, PAK \\ 3. Anaesthesia, DHQ Khanewal, Khanewale, PAK
}

Corresponding author: Farman Ali, farmiali@hotmail.com

\section{Abstract}

\section{Introduction}

Metacarpal and phalangeal fractures are common upper limb fractures due to direct blows, axial loading, and torsional loading injuries. The universal goal in treating all fractures for the patient to achieve normal motion, but the ideal technique for stabilization is still debated. For internal fixation, Kirschner wires (Kwires) or miniplates can be used, and each carries certain advantages. No previous study has compared Kwire use to miniplate use in treating metacarpal and phalangeal fractures. Therefore, we conducted this randomized control trial to evaluate the outcomes of K-wire and miniplate use in treating metacarpal and phalangeal fractures.

\section{Materials and methods}

This randomized controlled trial was conducted in the Department of Orthopaedic Surgery, Bahawal Victoria Hospital, from February 2017 to February 2018. Seventy-five patients were included in this study and randomly assigned into two groups. One group was treated with K-wire fixation, and the other group was treated with miniplate fixation. We assessed total active motion (TAM), range of motion (ROM), duration of injury, and complication rate. Data were analyzed using IBM SPSS Statistics for Windows, Version 23.0 (Armonk, NY: IBM Corp). P values $\leqslant 0.05$ were considered significant.

\section{Results}

Mean surgical time, pain scale, and time of union of K-wire treated patients was $38.63 \pm 3.64$ minutes, $4.17 \pm 1.11$, and $12.95 \pm 3.38$ weeks, respectively. The success of the union was noted in $38 \mathrm{~K}$-wire patients (95\%). Total active ROM was greater in miniplate fixation patients compared with K-wire treated patients, but this difference was statistically significant. Similarly, TAM was also greater in the miniplate fixation patients compared to the K-wire treated patients, but this difference was also not statistically significant.

Received 02/09/2020

Review began 02/13/2020 Review ended 02/13/2020 Published 02/19/2020

\section{() Copyright 2020}

Ahmed et al. This is an open access article distributed under the terms of the Creative Commons Attribution License CC-BY 4.0., which permits unrestricted use, distribution, and reproduction in any medium, provided the original author and source are credited.

\section{Conclusion}

Both K-wire fixation and miniplate fixation are equally effective in terms of TAM, ROM, and complications when used to treat metacarpal and phalangeal fractures.

\author{
Categories: Orthopedics \\ Keywords: k-wire, miniplate, metacarpal, phalangeal fracture, range of motion.
}

\section{Introduction}

Metacarpal and phalangeal fractures are common fractures of the upper limb associated with permanent loss of upper extremity dexterity [1]. The bones of metacarpal and phalanges are tubular with collective transverse arches and intrinsic longitudinal arches [2]. These bones are attached at the proximal and distal ends with ligamentous attachments and are concave on the palmer surface. Injury from direct blows, axial loading, and torsional loading are the main causes of metacarpal shaft fractures [3].

Displacement and any neurological and vascular injuries must be treated with early mobilization through open reduction and internal fixation to achieve maximum normal function and anatomy [4]. Early mobilization reduces joint stiffness, edema, and adherence to free normal gliding structures [5]. In every type of fracture, the ultimate goal is to achieve normal motion, but the technique of choice for stabilizing the fracture remains debated [6].

The ideal technique for stabilization and fixation would have a minimum cost, maximum bony union, and allow for proper rotation, length, alignment, and recovery of normal hand functioning without fear of 
displacement [7]. In internal fixation, Kirschner wires (K-wires) or miniplate can be used. K-wire use has some advantages over the miniplate approach such as advanced material, minimum dissection, technical ease, and availability of the material [8]. The miniplate, however, has modifications specially designed for hand surgery. Through the use of these specially designed plates, we can achieve extra rigidity and length maintenance $[9,10]$.

No previous studies are available that compare K-wire outcomes with miniplate outcomes in treating metacarpal and phalangeal fractures. We conducted this randomized control trial to evaluate the outcomes of K-wire use with miniplate use in treating metacarpal and phalangeal fractures.

\section{Materials And Methods}

This randomized controlled trial was conducted in the Department of Orthopedic Surgery of Bahawal Victoria Hospital, Bahawalpur, from February 2017 to February 2018. The study received ethical approval from our institutional ethics board, and informed consent was obtained from all patients studied. The study included all displaced fractures of the metacarpal and phalangeal bones with malrotation, irreducible, subcapital open fractures, intra-articular fractures, multiple traumas of the hand, and segmental bone loss presenting to the emergency ward. Patients with osteoporosis and firm cortical acquisition were excluded from the study. Non-probability consecutive sampling was used. Patients were divided into two equal groups randomly. One group was treated with K-wire fixation, and the other group was treated with miniplate fixation.

Patients were treated under digital block and mild sedation to flex and extend the fingers for assessment of digit movement. A dorsal skin incision exposed the fracture site, and the periosteum was incised longitudinally enough to cleanse and place the desired fixation. The fixation pin was drilled in retrograde from the fracture margin along the dorsoradial aspect of the metacarpal, then back down the shaft to reduce the fracture. The pin was inserted, and rotational alignment was maintained. The patient was asked to flex and extend the digits. If alignment was not proper, the pin was removed, and another pin was inserted. After surgery, a bulky dressing was done for five days, and the patient was asked to engage in active mobilization. Heavy lifting and gripping were not allowed for six weeks following the surgical procedure.

For metacarpal fractures, the site was exposed with a direct incision on the border of the radius and the first two metacarpals, and on the border of the ulna and the fifth metacarpal. A longitudinal incision was made between the third and fourth metacarpals to expose the fracture site. A mid-lateral incision exposed the phalangeal fracture. A lateral band was incised for optimum exposure of the proximal phalanx. the periosteum was incised and exposed by elevating the fracture to avoid violation of the gliding space, the periosteum, and the extensor tendon. The drill hole was made at the correct position in a single attempt. When fixation was secured, the original position of the periosteal layer was returned and sutured if needed. Soft dressing was applied after wound closure, and one day following the procedure, an active range of motion (ROM) exercise was started under the supervision of the surgeon.

The follow-up period was eight weeks. The surgical site was evaluated weekly, and x-rays were taken to observe the loss of reduction and monitor bone healing. Active ROM was measured, and patients were discharged once ROM peaked and the fracture had healed significantly. Data were analyzed using IBM SPSS Statistics for Windows, Version 23.0 (Armonk, NY: IBM Corp). We evaluated pain via the visual analogue scale, surgical time, success of the union, and complications. The mean and standard deviation was calculated for numerical data and frequency (percentages) were calculated for qualitative data. P-values of less than 0.05 was taken as statistically significant.

\section{Results}

Seventy-five patients (42 men, 33 women) were enrolled in this study. Forty patients (21 men, 19 women) were treated with K-wire fixation, and 35 patients ( 21 men, 14 women) were treated with miniplate fixation. The mean age and time injury of K-wire treated patients was $25.20 \pm 1.78$ years and $4.38 \pm 1.44$ hours, respectively. There were 12 open fractures (30\%) and 17 intraarticular fractures $(42.5 \%)$ in the K-wire group. For the miniplate group, the mean age and time injury was $25.51 \pm 2.18$ years and $4.88 \pm 1.23$ hours, respectively. There were nine open fractures (25.7\%) and 16 intraarticular fractures (45.7\%) in the miniplate group. The distribution of fracture categories was not statistically significant and is shown in Table 1 . 


\section{Cureus}

\begin{tabular}{|c|c|c|c|}
\hline Variable & K-wire $(n=40)$ & Miniplate $(n=35)$ & P-value \\
\hline \multicolumn{4}{|l|}{ Gender } \\
\hline Male & $21(52.5 \%)$ & $21(60 \%)$ & \multirow{2}{*}{0.514} \\
\hline Female & $19(47.5 \%)$ & $14(40 \%)$ & \\
\hline Age (years) & $25.20 \pm 1.78$ & $25.51 \pm 2.18$ & 0.496 \\
\hline Time injury (hours) & $4.38 \pm 1.44$ & $4.88 \pm 1.23$ & 0.106 \\
\hline Open fracture & $12(30 \%)$ & $9(25.7 \%)$ & 0.680 \\
\hline Intraarticular & 17 (42.5\%) & 16 (45.7\%) & 0.780 \\
\hline \multicolumn{4}{|l|}{ Fracture category } \\
\hline Metacarpal & $16(40 \%)$ & 15 (42.9\%) & \multirow{3}{*}{0.789} \\
\hline Phalanx & $25(50 \%)$ & $18(51.4 \%)$ & \\
\hline Thumb & $4(10 \%)$ & $2(5.7 \%)$ & \\
\hline
\end{tabular}

\section{TABLE 1: Demographic data}

The mean surgical time, pain scale, and time of union of K-wire treated patients was $38.63 \pm 3.64$ minutes, $4.17 \pm 1.11$, and $12.95 \pm 3.38$ weeks, respectively. Thirty-eight fractures had a successful union (95\%) shown in Table 2. The mean surgical time, pain scale, and time of union of miniplate fixation patients were $52.34 \pm 3.45$ minutes, $5.25 \pm 1.57$, and $11.80 \pm 2.38$ weeks, respectively. Thirty-four fractures had a successful union (97.1\%). Total active ROM was greater in miniplate fixation patients compared with K-wire patients, but this difference was not significant (Table 2). Similarly, total active motion (TAM) was also greater in miniplate fixation patients compared with K-wire treated patients, but the difference in TAM was not statistically significant. The distribution of different complications of both groups is presented in Table 3. 


\section{Cureus}

\begin{tabular}{|c|c|c|c|}
\hline Variable & K-wire $(n=40)$ & Miniplate $(n=35)$ & P-value \\
\hline \multicolumn{4}{|l|}{ Outcomes } \\
\hline Surgical time (minutes) & $38.63 \pm 3.64$ & $52.34 \pm 3.45$ & 0.000 \\
\hline Pain scale & $4.17 \pm 1.11$ & $5.25 \pm 1.57$ & 0.102 \\
\hline Time of union (weeks) & $12.95 \pm 3.38$ & $11.80 \pm 2.38$ & 0.485 \\
\hline Success of union & 38 (95\%) & 34 (97.1\%) & 0.637 \\
\hline \multicolumn{4}{|l|}{ Average ROM (degree) } \\
\hline \multicolumn{4}{|l|}{ MP } \\
\hline Normal & -- & -- & -- \\
\hline Metacarpal & $76.95 \pm 2.57$ & $85.71 \pm 1.94$ & 0.071 \\
\hline Phalanx & $79.32 \pm 2.51$ & $78.28 \pm 3.06$ & 0.210 \\
\hline Thumb & $76.57 \pm 1.79$ & $82.62 \pm 2.93$ & 0.354 \\
\hline \multicolumn{4}{|l|}{ PIP } \\
\hline Normal & -- & $110.82 \pm 3.39$ & -- \\
\hline Metacarpal & $101.05 \pm 4.95$ & $105.48 \pm 3.11$ & 0.101 \\
\hline Phalanx & $96.90 \pm 5.65$ & $97.62 \pm 1.78$ & 0.421 \\
\hline Thumb & $95.80 \pm 4.05$ & $97.51 \pm 2.02$ & 0.085 \\
\hline \multicolumn{4}{|l|}{ DIP } \\
\hline Normal & -- & $64.25 \pm 1.94$ & -- \\
\hline Metacarpal & $62.25 \pm 1.99$ & $64.31 \pm 2.60$ & 0.324 \\
\hline Phalanx & $59.95 \pm 2.84$ & $62.77 \pm 3.78$ & 0.357 \\
\hline Thumb & -- & -- & -- \\
\hline \multicolumn{4}{|l|}{ Total active motion } \\
\hline Normal & -- & $260.20 \pm 4.49$ & -- \\
\hline Metacarpal & $246.63 \pm 3.22$ & $254.37 \pm 3.44$ & 0.142 \\
\hline Phalanx & $216.43 \pm 4.18$ & $242.34 \pm 6.20$ & 0.247 \\
\hline Thumb & $210.35 \pm 5.26$ & $234.34 \pm 6.49$ & 0.09 \\
\hline
\end{tabular}

\section{TABLE 2: Study outcome variables}

MP:metacarpophalangeal joint; PIP: proximal interphalangeal joint; DIP: distal interphalangeal joint. 


\section{Cureus}

\begin{tabular}{|c|c|c|c|}
\hline Complications & K-wire $(n=40)$ & Miniplate $(n=35)$ & p-value \\
\hline Infection & $4(10 \%)$ & $1(2.9 \%)$ & \multirow{6}{*}{0.825} \\
\hline Implant loosening & $2(5 \%)$ & $1(2.9 \%)$ & \\
\hline Loss of reduction & $3(7.5 \%)$ & $2(5.7 \%)$ & \\
\hline Stiffness & $4(10 \%)$ & $3(8.6 \%)$ & \\
\hline Malunion & $2(5 \%)$ & $2(5.7 \%)$ & \\
\hline Total & 15 (37.5\%) & $9(25.8 \%)$ & \\
\hline
\end{tabular}

TABLE 3: Complications

\section{Discussion}

James et al. reported that $77 \%$ of fingers lost function when treated with closed reduction of an unstable phalangeal fracture [11]. These results were unsatisfactory due to the loss of active ROM at the phalangeal joint with K-wire fixation; only $8 \%$ of patients regained full phalangeal functions. James et al.'s results are comparable to our findings. Green et al. reported $69 \%$ of patients treated with closed reduction and percutaneous pin fixation of proximal phalangeal fractures had satisfactory results. They concluded that this technique was only useful for oblique fractures of the proximal phalanx [12].

One study reported 32 patients with hand fractures due to injury from low-velocity bullets were treated by cleansing the wound, debridement, splinting, and use of antibiotics [13]. No infection occurred, but unstable fractures yielded poor ROM at their associated joints-which aligns with our findings. Barton et al. reported $57 \%$ satisfactory results in patients with comminuted fractures, which also aligns with our results [13].

Huffaker et al. conducted a study on factors influencing reductions in ROM [14]. They reported satisfactory results in $67 \%$ of patients without considering any specific method of treatment. They reported a $20 \%$ decreased ROM in unfractured phalangeal bones of similar hands. Injuries that involve extensor and flexor tendons affected the end results. Strickland et al. reported that immobilization for longer than two weeks might decrease TAM [15]. About $25 \%$ of phalangeal shaft fractures treated with open reduction and fixation with K-wires yielded good TAM of $142^{\circ}$.

Lister et al. reported that phalangeal shaft fractures treated with K-wire fixation and immobilization of three weeks yielded improved results of nearly $157^{\circ} \mathrm{TAM}$. Lister et al. achieved a TAM of $199^{\circ}$ and recommended $\mathrm{K}$-wire fixation as the treatment of choice [16]. Belsky et al. concluded that closed reduction with internal fixation is better than open reduction-they observed excellent results in $69 \%$ of cases, $29 \%$ had good results, and $10 \%$ had fair to poor results. Belsky et al.'s findings are important and add to the debate on the proper management of phalangeal fractures [17].

Miniplate is a biomechanically effective tool for surgeons when a fracture is located at the phalangeal shaft. The miniplate is more flexible than K-wire fixation, which can slide through the bony union. In a study by Fyfe et al., fixation was found to be weaker when K-wire was used. Fyfe et al. found that fixation with miniplate yielded much better results [18]. Massengill et al. reported that miniplate fixation provides equal stabilization and results in better ROM and outcomes of TAM. They found that achieving normal phalangeal function was more consistent with miniplate use [19].

Miniplate provides significant stabilization, so mobilization and exercises for active ROM can start sooner. Soft dressing should be applied to allow for the early commencement of activities. Wutphiriya-angkul et al. reported that both $\mathrm{K}$-wire and miniplate techniques are equally effective in treating metacarpal and phalangeal fractures [13]. Both techniques required minimum time for the operation, and findings from that study are identical to ours in that both techniques are time-saving and equally effective when used in metacarpal and phalangeal fractures.

\section{Conclusions}

Both techniques K-wire fixation and miniplate fixation are equally effective in terms of TAM, ROM, and complications when used to treat metacarpal and phalangeal fractures.

\section{Additional Information \\ Disclosures}


Human subjects: Consent was obtained by all participants in this study. Bahawal Victoria Hospital Bahawalpur issued approval Ortho/BVH/2017. The IRB reviewed study proposal in detail and found no unethical aspect. And allow to conduct study in BVH Bahawalpur. IRB here by directed researchers to follow institutional guidelines. Animal subjects: All authors have confirmed that this study did not involve animal subjects or tissue. Conflicts of interest: In compliance with the ICMJE uniform disclosure form, all authors declare the following: Payment/services info: All authors have declared that no financial support was received from any organization for the submitted work. Financial relationships: All authors have declared that they have no financial relationships at present or within the previous three years with any organizations that might have an interest in the submitted work. Other relationships: All authors have declared that there are no other relationships or activities that could appear to have influenced the submitted work.

\section{References}

1. Başar H, Başar B, Başçı O, Topkar OM, Erol B, Tetik C: Comparison of treatment of oblique and spiral metacarpal and phalangeal fractures with mini plate plus screw or screw only. Arch Orthop Trauma Surg. 2015, 135:499-504. 10.1007/s00402-015-2164-3

2. Pandey R, Soni N, Bhayana H, Malhotra R, Pankaj A, Arora SS: Hand function outcome in closed small bone fractures treated by open reduction and internal fixation by mini plate or closed crossed pinning: a randomized controlled trail. Musculoskelet Surg. 2019,103, 99-105. 10.1007/s12306-018-0542-Z

3. $\mathrm{Xu} \mathrm{J}$, Zhang C: Mini-plate versus Kirschner wire internal fixation for treatment of metacarpal and phalangeal fractures in Chinese Han population: a meta-analysis. J Orthop Surg Res. 2015, 9:24. 10.1186/1749-799X-9-24

4. Verver D, Timmermans L, Klaassen RA, van der Vlies CH, Vos DI, Schep NWL: Treatment of extra-articular proximal and middle phalangeal fractures of the hand: a systematic review. Strat Traum Limb Recon. 2017, 12:63-76. 10.1007/s11751-017-0279-5

5. Venkatesh R, Kerakkanavar S: Functional outcome of closed metacarpal shaft fractures managed by lowprofile miniplate osteosynthesis: a prospective clinical study. J Orthop Allied Sci. 2017, 5:63-7. 10.4103/joas.joas 4517

6. Zhang B, Hu P, Yu KL, et al.: Comparison of AO titanium locking plate and screw fixation versus anterograde intramedullary fixation for isolated unstable metacarpal and phalangeal fractures. Orthop Surg. 2016, 8:316322. 10.1111/os.12271

7. Kim JY, Lee YK, Kong GM, Kim DY, Park JH, Jung YR: Comparison of intramedullary K-Wire nailing versus plate for fixation in metacarpal midshaft fracture. J Korean Orthop Assoc. 2016, 51:338-344. 10.4055/jkoa.2016.51.4.338

8. Al-Madawy AM, Elatta MM, Hasanin MM, Al-Nahal AA: The use of minilocked plate for management of unstable metacarpal fractures. J Hand Microsurg. 2016, 8:159-164. 10.1055/s-0036-1593730

9. von Kieseritzky J, Nordström J, Arner M: Reoperations and postoperative complications after osteosynthesis of phalangeal fractures: a retrospective cohort study. J Plast Surg Hand Surg. 2017, 51:458-462. 10.1080/2000656X.2017.1313261

10. Li G, Liu S, Chen G, et al.: Comparison of clinical outcomes of phalangeal fracture treated with dorsolateral approach or post-middle approach using AO mini titanium plate. Indian J Surg. 2015, 77:657-661. 10.1007/s12262-013-0968-3

11. James JIP: Fractures of the proximal and middle phalanges of the finger . Acta Orthop Scand. 1962, 32:40112. $10.3109 / 17453676208989599$

12. Green DP, Anderson JR: Closed reduction and percutaneous pin fixation of fractured phalanges . J Bone Joint Surg Am. 1973, 55:1651-4.

13. Wutphiriya-angkul S: Comparison of miniplate and K-wire in treatment of metacarpal and phalangeal fractures. Thai J Surg. 2009, 30:5-10.

14. Huffaker WH, Wray RC, Weeks PM: Factors influence final range of motion in the fingers of the hand . Reconstr Surg. 1979, 63:82-7. 10.1097/00006534-197901000-00013

15. Strickland JW, Steichen JB, Kleinman WB, Hastings H, Flynn N: Phalangeal fractures: factor influencing digital performance. Orthop Rev. 1982, 11:39-50.

16. Lister G: Intraosseous wiring of the digital skeletal. J Hand Surg. 1978, 3:427-35. 10.1016/S03635023(78)80135-X

17. Belsky MR, Eaton RG, Lane LB: Closed reduction and internal fixation of proximal phalangeal fractures . J Hand Surg. 1984, 9:725-9. 10.1016/S0363-5023(84)80023-4

18. Fyfe IS, Mason S: The mechanical stability of internal fixation of fractured phalanges . Hand. 1979, 11:50-4 10.1016/S0072-968X(79)80009-1

19. Massengill JE, Alexander H, Lagrana N, Mylod A: Phalangeal fracture model-quantitative analysis of rigidity and failure. J Hand Surg. 1982, 17:264-70. 10.1016/S0363-5023(82)80177-9 